\title{
Predominance and association risk of Blastocystis hominis subtype I in colorectal cancer: a case control study
}

\author{
Amr Mohamed Mohamed ${ }^{1,2^{*}}$, Mona Abdelfattah Ahmed ${ }^{3,4}$, Sabah Abdelghany Ahmed ${ }^{4}$, \\ Sherif Ahmed Al-Semany ${ }^{5,6}$, Saad Saed Alghamdi ${ }^{1}$ and Dina Abdulla Zaglool, ${ }^{7,8}$
}

\begin{abstract}
Background: Blastocystis, a genetically diverse intestinal parasite with controversial pathogenic potential, has increasingly been incriminated for diarrheal illness in immunocompromised individuals including colorectal cancer (CRC) patients. The aim of the current study was to assess the possible association between Blastocystis infection and CRC condition in Makkah, Saudi Arabia (KSA).

Methods: Stool samples were collected from 80 non-cancer (NC) and 138 cancer subjects including 74 CRC patients and 64 patients with other cancers outside gastrointestinal tract (COGT). Molecularly confirmed Blastocystis isolates were genetically grouped and subtyped using multiplex polymerase chain reaction with restriction fragment length polymorphism (PCR-RFLP) and sequence-tagged site primers-based PCR (PCR-STS), respectively.

Results: Blastocystis hominis were confirmed in 29.7, 25 and 15\% among CRC, COGT and NC patients, respectively. Obtained Blastocystis isolates were initially categorized into 2 groups ( $A$ and $C$ ), which were subsequently subtyped into 3 different subtypes; subtype-I (38\%), subtype-II (44\%) and subtype-V (22\%). Interestingly, subtype-I was the most predominantly detected subtype (54.5\%) among CRC patients with a significant association risk (COR 7.548; 95\% Cl: 1.629-34.987; $P=0.004)$.

Conclusion: To the best of our knowledge, the current study is the first to provide genetic insights on the prevalence of Blastocystis hominis among CRC patients in Makkah, KSA. Moreover, the study suggests for a possible association between subtype-I of Blastocystis hominis and CRC, which could indicate a potential influence of Blastocystis on CRC condition. Further studies are required to confirm this association risk and to investigate the possible underlying mechanism of postulated carcinogenic influence of Blastocystis hominis subtype-l.
\end{abstract}

Keywords: Blastocystis hominis, CRC, Genetic diversity, Subtypes-I, Association risk

\section{Background}

Blastocystis species remains one of the most common intestinal parasites in humans with a prevalence of up to $10 \%$ in developed countries, rising to $50-60 \%$ in developing countries $[1,2]$. It is considered one of the most commonly encountered non-fungal eukaryotic organisms in human fecal samples [3]. Blastocystis is an enteric protozoon found in the intestinal tract of humans and

\footnotetext{
* Correspondence: amrmohamed2004@yahoo.com

'Laboratory Medicine, Faculty of Applied Medical Sciences, Umm Al-Qura University, Makkah 7607, Saudi Arabia

${ }^{2}$ Clinical Laboratory Diagnosis, Department of Animal Medicine, Faculty of Veterinary Medicine, Assiut University, Assiut, Egypt

Full list of author information is available at the end of the article
}

a wide range of animal hosts [4]. Morphologically, Blastocystis is a highly polymorphic organism that takes several different forms during its life cycle including vacuolar, cystic, amoeboid, granular, multivacuolar, and avacuolar forms $[1,5]$.

The pathogenicity of these protozoa is still controversial and inconclusive with non-specific symptoms such as abdominal pain, nausea, vomiting, anorexia, flatulence, weight loss, and acute or chronic diarrhea [6, 7]. Similar to other intestinal parasitism and chronic gastrointestinal illnesses such as irritable bowel syndrome (IBS), Blastocystis infection is usually associated with alternate episodes of diarrhea, normal defecation or even constipation. 
Symptomatic Blastocystis infection has been encountered more commonly among patients of IBS as well as other immunocompromised patients $[3,6,8]$.

Molecular studies revealed that the parasite is characterized by an extensive genetic diversity in both humans and animals with a worldwide distribution [9-15]. At least 10 subtypes (ST), ST1 to ST10, have been recognized based on the small subunit ribosomal RNA (SSU rRNA) gene sequence [16]. In addition, three novel subtypes (ST11-ST13) have been identified from captive animals in the zoo [17]. At present, only ST1 to ST9 are considered to colonize in humans $[7,17]$. This genetic diversity has supported the hypothesis that the variability in symptoms in patients positive for Blastocystis could be due to different pathogenic potential among the subtypes [18-21].

Prevalence studies of Blastocystis in immunocompromised individuals have been confined to HIV/AIDS patients and there is general lack of information on the prevalence of the organism in other immunocompromised individuals such as colorectal cancer patients. Therefore the current study aimed to assess the possible relationship between Blastocystis infection and malignancy with special reference to CRC. The frequency of Blastocystis infection among CRC patients in comparison with other cancer and non-cancer patients were investigated. In addition, the study also aimed to assess the association potential of genetically identified subtype(s) of encountered Blastocystis infection with CRC in Makkah, KSA. This represents the first study to explore the genetic diversity of encountered Blastocystis isolates and to assess their association significance with colorectal cancer in Makkah, KSA.

\section{Methods}

\section{Study subjects}

This was a prospective case control study. A total of 218 stool samples were collected from recruited participants attending King Abdulla Medical city (KAMC), Makkah, KSA during the period extended from April 2013 to March 2015. Recruited participants belonged to two main groups. The first group included recently diagnosed patients with malignancy (138) and referred to as cancer patients $(\mathrm{CP})$ while the second group composed of normal subjects visiting the hospital for routine checkup (80) and referred to as non-cancer patients (NC). The cancer patients were categorized into two subgroups; colorectal cancer group (CRC), which included 74 subject and cancers outside gastrointestinal tract group (COGT), which included 64 patients (14 non hogken lymphoma; 11 malignant neoplasm of bladder; 15 malignant neoplasm of uterine adnexa; 9 malignant neoplasm of larynx and 15 malignant neoplasm of breast). Exclusion criteria included any suspected patient started anti-cancer treatment regime and/or receiving any anti-parasitic medication. Ethical approval for the study was obtained in accordance with the declaration of Helsinki from the Ethics Committee of the Faculty of Applied Medical Sciences, Umm Al-Qura University (AMSEC 10-18-2-2013) and Biomedical Research Ethics committee of King Abdullah Medical City. All investigated patients signed acknowledgment consents to declare their participation agreement.

\section{Isolation and conventional identification of Blastocystis}

Blastocystis parasites were isolated from suspected stool samples by in vitro cultivation at $37{ }^{\circ} \mathrm{C}$ using Jones' medium supplemented with $10 \%$ horse serum for $72 \mathrm{~h}$. [22]. Suspected cultures were then sub-cultured in duplicate using Jones' medium at $37{ }^{\circ} \mathrm{C}$ for 3 additional days. Afterwards, for each suspected isolate, one culture medium was subjected to microscopic examination for conventional identification of suspected Blastocystis, while the second culture medium was kept at $-20{ }^{\circ} \mathrm{C}$ for further molecular studies.

\section{Molecular identification of isolated Blastocystis}

Genomic DNA was isolated from cultures of conventionally identified Blastocystis as previously described with few modifications [23]. Briefly, frozen culture media were thawed at room temperature and the suspected Blastocystis were harvested by centrifugation at $500 \times \mathrm{g}$ for $5 \mathrm{~min}$ and washed with sterile phosphate- buffered saline (PBS) ( $\mathrm{pH}$ 7.4) for 5 times. Obtained cell pellets were then lysed using lysis buffer $(20 \mathrm{mM}$ Tris- $\mathrm{HCl}$ buffer, pH 8.0, $100 \mathrm{mM} \mathrm{NaCl}, 25$ mM EDTA, pH 8.0) containing $1 \%$ SDS and $0.5 \mathrm{mg}$ Proteinase $\mathrm{K} / \mathrm{ml}$ (Fermentas, USA) and incubated at $55{ }^{\circ} \mathrm{C}$ overnight. Genomic DNA was then extracted with phenol/chloroform/ isoamyl alcohol. Extracted DNA was then precipitated in 2 vol of ice-cold ethanol containing $0.3 \mathrm{M}$ sodium acetate $(\mathrm{pH}$ 5.2). Obtained DNA pellets were first washed in $70 \%$ ice-cold ethanol, and then was resuspended in $50 \mu \mathrm{l}$ Tris-EDTA (TE) buffer $(10 \mathrm{mM}$ Tris, $1 \mathrm{mM}$ EDTA, pH 8.0). DNA concentration of each sample was determined using the BioSpec-nano (Shimadzu Corporation, Japan) and its quality and integrity was tested using the A260/A280 ratio.

Identification of Blastocystis isolates was confirmed by molecular amplification of the conserved $1.1 \mathrm{Kbp}$. Target of SSU rRNA gene using previously described primers Blas-F: (GGA GGT AGT GAC AAT AAA TC) and Blas-R: (ACT AGG AAT TCC TCG TTC ATG) [24]. Amplification protocol was carried out as previously described with some modification [25]. Briefly, $5 \mu \mathrm{l}$ of template DNA $(10 \mathrm{ng} / \mu \mathrm{l})$ were used in a total reaction volume of $50 \mu \mathrm{l}$. The reaction mix included PCR buffer $(20 \mathrm{mmol}$ Tris-HCL (pH 8.4) and $50 \mathrm{mmol}$ $\mathrm{KCl}$ ), $0.1 \mathrm{mmol}$ each of dNTP (deoxyribonucleotide triphosphate), $1.5 \mathrm{mmol}$ of $\mathrm{MgCl} 2,50 \mathrm{pmol}$ of each primer, 
and 1.5 U of HotStar HiFidelity Polymerase (Qiagen). PCR condition consisted of an initial denaturation step at $95{ }^{\circ} \mathrm{C}$ for $10 \mathrm{~min}$ followed by 35 cycles of denaturation at $95{ }^{\circ} \mathrm{C}$ for $1 \mathrm{~min}$, annealing at $53{ }^{\circ} \mathrm{C}$ for $30 \mathrm{~s}$, and extension at $72{ }^{\circ} \mathrm{C}$ for $1 \mathrm{~min}$.

\section{Grouping and subtyping of Blastocystis by PCR-RFLP and PCR-STS analysis}

Grouping of Blastocystis isolates was performed by RFLP analysis of the amplified $1.1 \mathrm{kbp}$. target of SSU rRNA gene using SpeI restriction enzyme (New England BioLabs Inc., MA, USA). Blastocystis isolates were grouped according to size of obtained digestion products as previously described [26]. Grouped Blastocystis isolates were then subjected to subtyping analysis. For this purpose, seven pairs of sequence-tagged site (STS) previously described primers [9] were used for conducting PCR-STS analysis. Primer sets names and sequences as well as predicted product size are shown in Table 1. PCR-STS protocol was conducted as previously described with little modification $[9,23]$. Briefly, $5 \mu \mathrm{l}$ of template DNA $(10 \mathrm{ng} / \mu \mathrm{l})$ were used in a total reaction volume of $50 \mu \mathrm{l}$. The reaction mix included PCR buffer (20 mmol Tris-HCL (pH 8.4) and $50 \mathrm{mmol} \mathrm{KCl}$ ), $0.1 \mathrm{mmol}$ each of dNTP (deoxyribonucleotide triphosphate), $1.5 \mathrm{mmol}$ of $\mathrm{MgCl} 2,25 \mathrm{pmol}$ of each primer, and $1.5 \mathrm{U}$ of HotStar HiFidelity Polymerase (Qiagen). The PCR amplification started with an initial denaturation step at $95{ }^{\circ} \mathrm{C}$ for $10 \mathrm{~min}$, followed by 35 cycles including denaturation at $95{ }^{\circ} \mathrm{C}$ for $1 \mathrm{~min}$, an annealing at $56{ }^{\circ} \mathrm{C}$ for $30 \mathrm{~s}$, and an extension step at $72{ }^{\circ} \mathrm{C}$ for $1 \mathrm{~min}$. All PCR amplifications were carried out using Applied Biosystems Veriti Thermal Cycler (ThermoFisher Scientific Inc.) After PCR, $10 \mu \mathrm{l}$ of the PCR product was mixed with $5 \mu \mathrm{l}$ dye mixture $(0.25 \%$ bromophenol blue and $0.25 \%$ xylene cyanol in $15 \%$ Ficoll type 400) and electrophoresed in $1 \mu \mathrm{l}$ Tris-acetate-EDTA buffer through a $2 \%$ agarose gel containing ethidium bromide $(0.5 \mu \mathrm{g} / \mathrm{mL})$. Bands of the appropriate size were visualized using a Molecular Imager ${ }^{\ominus}$ Gel Doc $^{\mathrm{TM}}$ XR System (Bio-Rad Laboratories) according to the manufacturer's instructions and identified by comparison with a 100-bp DNA ladder (DNA molecular weight marker Promega) using Image Lab version 5 (Bio-Rad Laboratories).

\section{Statistical analysis}

Statistical analysis of the results was performed using SPSS version 16 (SPSS, Chicago, IL). The frequencies of Blastocystis infection and/or its subtypes among different groups of investigated patients were assessed using crosstabulation followed by Chi square $(X 2)$ test or Fischer's exact test. A crude odds ratio (COR) with 95\% confidence interval (CI) was calculated for frequency analysis as appropriate for assessment of possible association risk. All tests performed were two-sided and $P$ value $<0.05$ was considered significant.

\section{Results}

Detection and identification of Blastocystis isolates

Blastocystis was initially identified conventionally by microscopic visualization of Blastocystis stages in culture media. Identification was then confirmed genetically by PCR amplification of the conserved Blastocystis hominisspecific $1.1 \mathrm{Kbp}$. target of the SSU rRNA gene (Fig. 1). Out of a total of 218 fecal samples from suspected patients with gastrointestinal illnesses, Blastocystis hominis were identified in 50 (22.9\%) samples. This included $22(29.7 \%)$ of CRC patients, 16 (25\%) of COGT patients and $12(15 \%)$ of NC patients (Table 2). A significant difference $(P<0.05)$ of Blastocystis infection frequency was evident between $\mathrm{CP}$ group and $\mathrm{NC}$ groups as well as between $\mathrm{CRC}$ and NC groups. However, no significant difference $(P>0.05)$ was evident between COGT and NC groups (Table 2).

Table 1 Different STS primer sets used for differential identification of Blastocystis subtypes along with expected amplified product sizes

\begin{tabular}{|c|c|c|c|c|}
\hline STS primer set & GenBank accession no. & Sequences & Product size & Subtype \\
\hline SB83 & AF166086 & $\begin{array}{l}\text { F-GAAGGACTCTCTGACGATGA } \\
\text { R-GTCCAAATGAAAGGCAGC }\end{array}$ & 351 & 1 \\
\hline SB155 & AF166087 & $\begin{array}{l}\text { F-ATCAGCCTACAATCTCCTC } \\
\text { R-ATCGCCACTTCTCCAAT }\end{array}$ & 650 & $\|$ \\
\hline SB227 & AF166088 & $\begin{array}{l}\text { F-ATCAGCCTACAATCTCCTC } \\
\text { R-ATCGCCACTTCTCCAAT }\end{array}$ & 526 & III \\
\hline SB332 & AF166091 & $\begin{array}{l}\text { FGCATCCAGACTACTATCAACATT } \\
\text { R-CCATTTCAGACAACCACTTA }\end{array}$ & 338 & IV \\
\hline SB340 & AY048752 & $\begin{array}{l}\text { F-TGTTCTTGTGTCTTCTCAGCTC } \\
\text { R-TTCTTTCACACTCCCGTCAT }\end{array}$ & 704 & V \\
\hline SB336 & AY048751 & $\begin{array}{l}\text { F-GTGGGTAGAGGAAGGAAAACA } \\
\text { R-AGAACAAGTCGATGAAGTGAGAT }\end{array}$ & 317 & $\mathrm{Vl}$ \\
\hline SB337 & AY048750 & $\begin{array}{l}\text { F-GTCTITCCCTGTCTATTCTGCA } \\
\text { R-AATTCGGTCTGCTTCTTCTG }\end{array}$ & 487 & VII \\
\hline
\end{tabular}




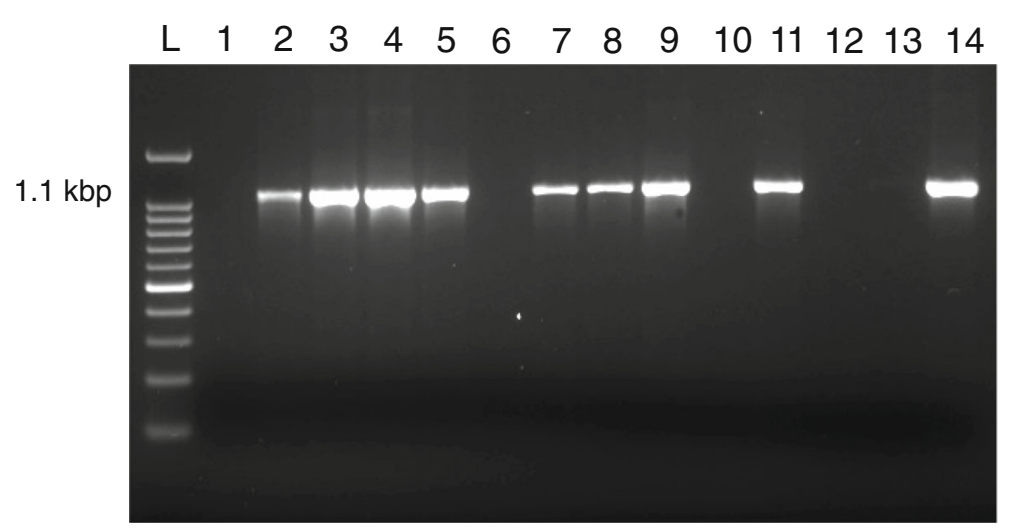

Fig. 1 Representative 1\% agarose gel showing the amplification of the Blastocystis-specific $1.1 \mathrm{kbp}$ target of the SSU of rRNA gene. (Lane L) shows 100 bp DNA ladder; (Lane 1) represents negative control; (Lanes 2,3,4,5,7,8,9,11and 14) represent positive results for Blastocystis; (Lanes $6,10,12$ and 13) represent negative results for Blastocystis

Moreover, results revealed an associated risk (COR 2.153; 95\% CI: $1.053-4.417 ; \quad P=0.044)$ between Blastocystis infection and cancer condition with a higher risk of association (COR 2.397; 95\% CI: $1.087-5.286 ; P=0.033$ ) in CRC group but not in the COGT group.

\section{Genetic grouping and subtyping of Blastocystis isolates}

Based on RFLP analysis of the amplified $1.1 \mathrm{Kbp}$ target of the SSU rRNA gene, 2 Blastocystis groups were reported; group A (230 bp., 430 bp. and 450 bp.) and group C (470 bp. and 650 bp.) (Fig. 2). Accordingly, 39 isolates of obtained Blastocystis hominis from suspected patients were categorized as group A while the rest 11 isolates were categorized as group C. further genotypic analysis of recovered Blastocystis hominis based on the predicted size of obtained amplicons after PCR-STS assay resulted in subtyping of group A isolates into 2 different subtypes (I and II) and that of group C as only one subtype (V) (Fig. 3). Overall, $40 \%$ of recovered Blastocystis hominis were identified as subtype II, $38 \%$ as subtype I, and $22 \%$ were identified as subtype V. In relation to type of patients, subtype I was predominant

Table 2 Frequency of Blastocystis infection among CP including CRC and COGT groups as well as NC group of investigated patients

\begin{tabular}{|c|c|c|c|c|c|}
\hline \multirow{2}{*}{\multicolumn{2}{|c|}{$\begin{array}{l}\text { Investigated } \\
\text { groups (no.) }\end{array}$}} & \multicolumn{4}{|c|}{ Blastocystis infection } \\
\hline & & \multicolumn{2}{|c|}{$\begin{array}{l}\text { Positive cases } \\
\text { no. (\%) }\end{array}$} & \multicolumn{2}{|c|}{$\begin{array}{l}\text { Negative cases } \\
\text { no. (\%) }\end{array}$} \\
\hline \multirow[t]{2}{*}{ CP (138) } & CRC (74) & $38(27.5)^{a}$ & $22(29.7)^{b}$ & $100(72.5)$ & $52(70.3)$ \\
\hline & COGT (64) & & $16(25)$ & & $48(75)$ \\
\hline \multicolumn{2}{|l|}{ NC (80) } & \multicolumn{2}{|l|}{$12(15)$} & \multicolumn{2}{|l|}{$68(85)$} \\
\hline \multicolumn{2}{|c|}{ Total (218) } & \multicolumn{2}{|l|}{$50(22.9)$} & \multicolumn{2}{|l|}{$168(77.1)$} \\
\hline
\end{tabular}

Cancer patients (CP); Colorectal cancer (CRC); COGT (Cancer outside gastrointestinal tract); Non cancer (NC)

${ }^{a}$ Blastocystis infection in overall cancer group as compared to NC group $(P=0.044)$

${ }^{b}$ Blastocystis infection in CRC group as compared to NC group $(P=0.033)$
(44.7\%) in cancer patients while subtype II was predominant (58.3\%) among non-cancer patients. Among cancer patients, subtype I was the predominant subtype (54.5\%) among CRC patients, while subtype II was predominant (43.7\%) among COGT patients (Table 3). Subtype I showed significant higher frequency $(P<0.05)$ in CRC group as compared to other recovered subtypes in the same group. With regard to frequency significance among different groups, subtype I showed significant higher frequency $(P<0.05)$ in $\mathrm{CP}$ as compared to NC group. On the other hand, frequency variation between different cancer patients groups revealed significant higher frequency $(P<0.05)$ of subtype $I$ in $C R C$ as compared to COGT group (Table 3). Interestingly, an association risk between Blastocystis subtype-I and cancer condition was evident (COR 5.479; 95\% CI: 1.232-24.374; $P=0.013$ ) with

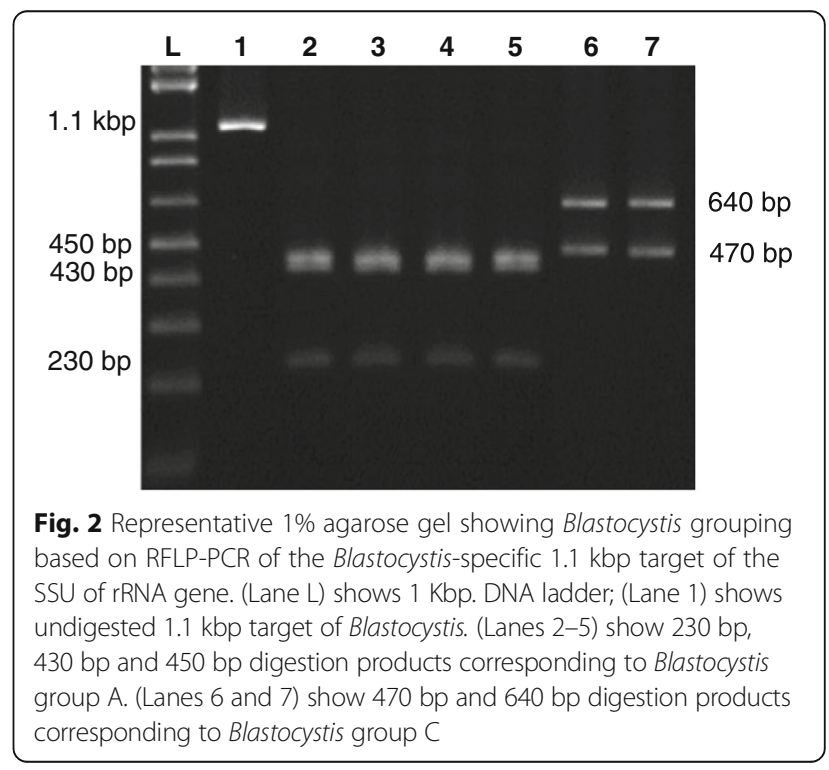


Table 3 Frequency of different Blastocystis subtypes isolated from CP including CRC and COGT groups and NC group of investigated patients

\begin{tabular}{|c|c|c|c|c|c|c|c|}
\hline \multirow{2}{*}{\multicolumn{2}{|c|}{ Investigated groups (n) }} & \multicolumn{6}{|c|}{$\begin{array}{l}\text { Recovered subtypes of Blastocystis } \\
\text { no. (\%) }\end{array}$} \\
\hline & & I & & $\|$ & & V & \\
\hline \multirow[t]{2}{*}{ CP (38) } & CRC (22) & $17(44.7)^{a}$ & $12(54.5)^{b, c, d, e}$ & $13(34.2)$ & $6(27.3)$ & $8(21.1)$ & $4(18.2)$ \\
\hline & COGT (16) & & $5(31.3)$ & & $7(43.7)$ & & $4(25)$ \\
\hline NC (12) & & $2(16.7)$ & & $7(58.3)$ & & $3(25)$ & \\
\hline Total (50) & & $19(38)$ & & $20(40)$ & & $11(22)$ & \\
\hline
\end{tabular}

Cancer patients (CP); Colorectal cancer (CRC); COGT (Cancer outside gastrointestinal tract); Non cancer (NC)

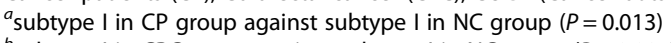

${ }^{b}$ subtype I in CRC group against subtype I in NC group $(P=0.004)$

'subtype I in CRC group against subtype I in COGT group $(P=0.024)$

${ }^{d}$ subtype I in CRC group against subtype II in the same group $(P=0.019)$

${ }^{e}$ subtype I in CRC group against subtype $\mathrm{V}$ in the same group $(P=0.018)$

a greater risk of association (COR 7.548; 95\% CI: 1.629 34.987; $P=0.004$ ) in CRC group.

All raw data of the current work were made available as an additional file (Additional file 1).

\section{Discussion}

After dietary factors and tobacco smoke, infectious diseases represent the third leading cause of cancer worldwide. The International Agency on Research of Cancer (IARC) has estimated that $16 \%$ of cancer worldwide is initiated by infectious agents including parasites [27]. With regard to relation between parasitic infection and cancerous conditions, few studies investigated the association between Blastocystis hominis infection and colorectal cancer. The recently postulated potential carcinogenic effect of Blastocystis hominis infection in human host especially in colorectal cancer patients $[28,29]$ signifies the need for screening of colorectal cancer patients for Blastocystis hominis infection. Therefore the current study aimed to investigate the association risk of Blastocystis hominis infection and its subtypes in relation to CRC patients of Makkah region, KSA.

The over all rate of Blastocystis infection as revealed in the current study was $22.9 \%$. The current finding is comparable to previously reported frequencies in several countries including Saudi Arabia (17.5\%) [30], Malaysia (25.7\%) [31], Jordan (25\%) [32], Egypt (31\%) [33], 25.78\% in Venezuela [34] and 22.9\% in Argentina [35]. On the other hand, significantly lower infection rates ranged between 9 and 12\% were recently reported in Saudi Arabia [36, 37]. The currently recorded higher infection rate could be attributed to the type of targeted patients in the comparable studies where the patients were predominantly immune-competent. Interestingly, the currently recorded rate of Blastocystis hominis infection among cancer patients is apparently higher than figures (7.7-13\%) previously recorded among other cancer patients [23, 38, 39]. With regard to type of patients, current study revealed significant higher frequency $(P=0.044)$ of Blastocystis infection in $\mathrm{CP}$ group as compared to NC group. This finding might support the association risk of the parasite with

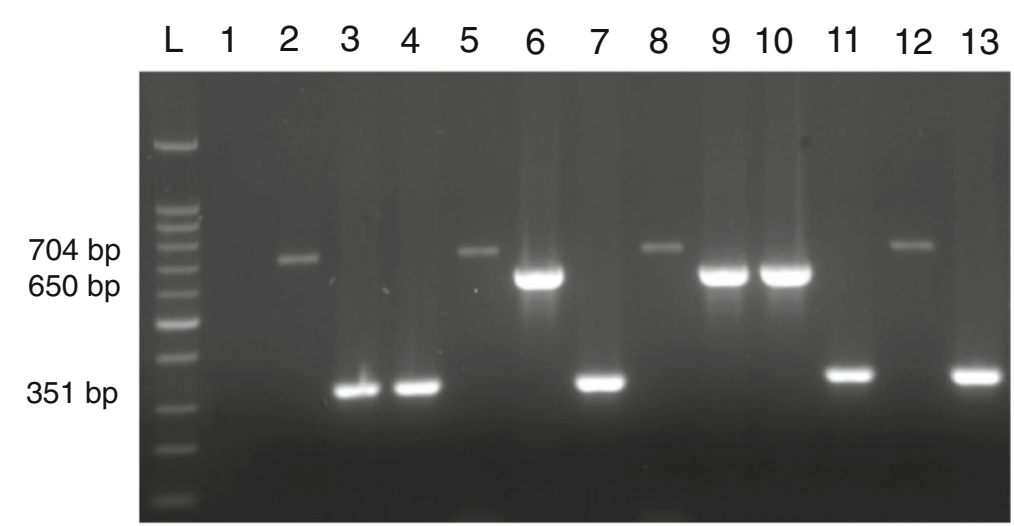

Fig. 3 Representative 1\% agarose gel showing Blastocystis subtyping based on PCR-STS analysis. (Lane L) shows 100 bp DNA ladder; (Lane 1) represents negative control. (Lanes 2,5,8 and 12) show 704 bp PCR products and represent Blastocystis subtype-V. (Lanes 3,4,7,11 and 13) show 351 bp PCR products and represent Blastocystis subtype-I. (Lanes 6,9 and 10) show 650 bp PCR products and represent Blastocystis subtype-II 
immunocompromised condition [23] and denotes that Blastocystis infection is not rare and should be looked for routinely in immunocompromised patients. However, with regard to type of cancer, the current study revealed significant $(P=0.033)$ higher frequency of Blastocystis infection only in CRC and not COGT group as compared to NC group. These findings contradict the notion of association between Blastocystis infection and immunocompromised conditions, yet denote that Blastocystis infection is more likely associated with those immunocompromised conditions with gastrointestinal affections as CRC. This likely association was statistically validated in the current study (COR 2.397; 95\% CI: 1.087-5.286; $P=0.033$ ).

Genetic diversity of Blastocystis hominis and its worldwide distribution has been evidenced [9-13]. Genotyping of the parasite has received great attention lately in a trial to link the different pathogenic behaviors of the parasite to its different subtypes. Based on the RFLP analysis of the small subunit ribosomal RNA gene, Blastocystis hominis are classified into four groups as previously described [26]. In the current study PCR-RFLP analysis revealed that most of the obtained isolates from suspected patients with gastrointestinal symptoms belonged to group A (78\%) while the rest of the isolates were found belonging to group C (22\%). Further subtyping of obtained isolates was carried out using PCR-STS assay as previously described [9]. Dissimilar to previous studies, which usually reveal the predominance of one subtype among investigated local population $[22,24,40]$, the current study revealed the presence of 3 different subtypes (I, II and V) among investigated patients. The detection of multiple subtypes could be due to the exceptional setting of the study. Makkah, where the current study was conducted, is a unique place in Saudi Arabia and the entire world. Annually, it receives more than three million pilgrims during the pilgrimage season in addition to several other million visitors during the whole year from allover the world $[41,42]$. This could have contributed to the acquisition of different Blastocystis hominis subtypes from different worldwide settings. In disagreement with previous studies, which had shown the predominance of subtype III among patients with chronic gastrointestinal illness in Malaysia [22], Singapore [24], Egypt [43], Turkey [44], USA [45] and Iran [46], interestingly, the current study have showed the predominance of subtype I and II (38 and 40\%, respectively) among targeted patients in Makkah. However, the current finding was in agreement with a previous study in central Thailand, where two subtypes (ST1 and ST2) were found predominant among schoolchildren of a rural community [47]. In the current study subtype II, most likely the one that is non-pathogenic [19], was the most predominantly detected subtype among investigated patients. On the other hand, subtype I, the second most predominately detected subtype among investigated patients, is believed to be one of the known pathogenic subtypes that were implicated in several human diseases and believed to be of animal origin with a zoonotic potential $[9,13]$. Evaluation of current study results revealed significant predominance ( $P=0.019$ and $P=0.018$, respectively) of subtype $\mathrm{I}$ as compared to other recovered subtypes (II and V, respectively) in CRC patients. Interestingly, the significant predominance of subtype I among CP group as compared to NC patients included highly significant predominance $(P=0.004)$ in $C R C$ group and not COGT group. Moreover, a strong association risk (COR 7.548; 95\% CI: 1.629_ 34.987; $P=0.004$ ) was evident between Blastocystis hominis subtype-I infection and CRC condition. This interesting finding supports the postulated carcinogenic effect of certain Blastocystis hominis subtypes and their possible influence on colorectal cancer. Recently, in vitro studies documented the ability of Blastocystis hominis to induce the growth of colorectal cancer cell lines via inhibiting the apoptotic effect of colon cancer cells. Furthermore, isolated antigens of Blastocystis hominis isolates were shown to promote the proliferation of cancer cells via down-regulation of host immune cellular responses [28, 29].

Growing data has evidenced the zoonotic potential of Blastocystis spp., where comparable genetic sequences were documented in a number of studies between different Blastocystis spp. isolated from both human and animals [48-50]. Moreover, some specific Blastocystis hominis subtypes were identified in both humans and animals. Subtype I is a common subtypes that had been identified in both human and a wide range of animal species including pigs, horses, monkeys, cattle, rodents, chickens, quails, and pheasants $[10,50,51]$. Other subtypes were also implicated in both human and animal infections with a potential zoonotic ability like subtype $\mathrm{V}$, the least predominant subtype encountered in the current study, which was reported in both human and dogs from the same sitting in Thailand [49]. In general, it was reported that population closely associated with animals has a higher prevalence of blastocystosis when compared with those not associated with animals [52]. With regard to the current study, the association risk between investigated suspected patients and animals was not inspected. However, it worth mentioning that many residents at Makkah region have some sort of association with animals particularly sheep, goat and camels. Moreover, drinking unpasteurized or even raw milk from dairy animals, a trend that is widely practiced in the region is a potential risk factor for disease transmission from animals to human [3]. Nevertheless, further epidemiologic studies need to be conducted to provide additional evidences to confirm the postulated role of 
zoonotic transmission of the disease to human population in Makkah, KSA.

\section{Conclusions}

The current study is the first to provide genetic insights on the prevalence of Blastocystis hominis among CRC patients in Makkah, KSA. Interestingly, the current results suggested a possible association between Blastocystis hominis subtype-I and CRC condition, which postulate a potential influence of this pathogen on carcinogenesis of CRC. In deed, these findings need to be confirmed via further controlled epidemiologic and topographic investigations to confirm the proposed association risk and to reveal other possible risk factors that could contribute to the condition. In addition, further studies are required to explore the underlying mechanism of the postulated carcinogenic influence of this pathogen.

\section{Additional file}

Additional file 1: Raw results data of different patient groups. Description of data: The original numbers and information of different groups of investigated patients along with the raw data of the obtained results. (XLSX $50 \mathrm{~kb})$

\section{Acknowledgements}

The authors would like to thank Mr. Mohammed E. Naeem, King Abdullah Medical City, Makkah, KSA and Mr. Ahmed A. Althagafi, Faculty of Applied Medical Sciences, Umm Al-Qura university for their valuable contribution in collection, handling and archiving of related stool specimens.

\section{Funding}

The current study was supported by a research grant \# 43409023 from the Institute if Scientific Research (ISRRIH), Umm Al-Qura University, Saudi Arabia.

\section{Availability of data and materials}

All data generated or analyzed during this study are included in this published article and its supplementary information files.

\section{Authors' contributions}

AMM, has made substantial contributions to the conception and design of the study, analysis and interpretation of data, drafting and critically revising the manuscript. MAA, contributed in the collection and examination of samples, analysis and interpretation of data. SAA, contributed in the design of the study, analysis and interpretation of data. ShAA, was responsible for recruitment and classification of included cancer patients. SSA, contributed in analysis and interpretation of data and drafting and revising of the manuscript. DAZ, contributed in the collection and examination of samples. All authors gave final approval of the version to be published, and agree to be accountable for all aspects of the work.

\section{Competing interests}

The authors declare that they have no competing interests.

\section{Consent for publication}

Not applicable.

\section{Ethics approval and consent to participate}

All procedures followed were in accordance with the ethical standards of on human research and in accordance with the Helsinki Declaration. Ethical approval for the study was obtained from the Ethics Committee of the Faculty of Applied Medical Sciences, Umm Al-Qura University (AMSEC 10-18-2-2013) and approved by the Biomedical Research Ethics committee of King Abdullah
Medical City. All investigated patients signed acknowledgment consents to declare their participation agreement.

\section{Publisher's Note}

Springer Nature remains neutral with regard to jurisdictional claims in published maps and institutional affiliations.

\section{Author details}

${ }^{1}$ Laboratory Medicine, Faculty of Applied Medical Sciences, Umm Al-Qura University, Makkah 7607, Saudi Arabia. ${ }^{2}$ Clinical Laboratory Diagnosis, Department of Animal Medicine, Faculty of Veterinary Medicine, Assiut University, Assiut, Egypt. ${ }^{3}$ Medical Parasitology, King Abdullah Medical City, Makkah, Saudi Arabia. ${ }^{4}$ Parasitology Department, Faculty of Medicine, Ain-Shams University, Cairo, Egypt. ${ }^{5}$ Oncology, King Abdullah Medical City, Makkah, Saudi Arabia. ${ }^{6}$ Department of Internal Medicine, Medical Oncology, Mansoura University, Mansoura, Egypt. ${ }^{7}$ Medical Parasitology, Al-Noor Specialist Hospital, Makkah, Saudi Arabia. ${ }^{8}$ Parasitology Department, Faculty of Medicine, Assiut University, Assiut, Egypt.

Received: 11 February 2017 Accepted: 6 April 2017

Published online: 12 April 2017

References

1. Stenzel DJ, Boreham PF. Blastocystis hominis revisited. Clin Microbiol Rev. 1996:9(4):563-84.

2. Tan KS. Blastocystis in humans and animals: new insights using modern methodologies. Vet Parasitol. 2004;126(1-2):121-44. doi:10.1016/j.vetpar. 2004.09.017.

3. Stensvold CR, Lewis HC, Hammerum AM, Porsbo LJ, Nielsen SS, Olsen $\mathrm{KE}$, et al. Blastocystis: unravelling potential risk factors and clinical significance of a common but neglected parasite. Epidemiol Infect. 2009:137(11):1655-63. doi:10.1017/S0950268809002672.

4. Menounos PG, Spanakos G, Tegos N, Vassalos CM, Papadopoulou C, Vakalis NC. Direct detection of Blastocystis sp. in human faecal samples and subtype assignment using single strand conformational polymorphism and sequencing. Mol Cell Probes. 2008:22(1):24-9. doi:10.1016/.j.mcp.2007.06.007.

5. Yoshikawa H, Abe N, Iwasawa M, Kitano S, Nagano I, Wu Z, et al. Genomic analysis of Blastocystis hominis strains isolated from two long-term health care facilities. J Clin Microbiol. 2000;38(4):1324-30.

6. Ok Uz, Cirit M, Uner A, Ok E Akcochicek F Basci A and Ozcel MA. Cryptosporidiosis and blastocystosis in renal transplant recipient. Nephron. 1997;75:171-74.

7. Rene BA, Stensvold CR, Badsberg JH, Nielsen HV. Subtype analysis of Blastocystis isolates from Blastocystis cyst excreting patients. Am J Trop Med Hyg. 2009;80(4):588-92.

8. Yakoob J, Jafri W, Beg MA, Abbas Z, Naz S, Islam M, et al. Irritable bowel syndrome: is it associated with genotypes of Blastocystis hominis. Parasitol Res. 2010;106(5):1033-8. doi:10.1007/s00436-010-1761-X.

9. Yoshikawa H, Wu Z, Kimata I, Iseki M, Ali IK, Hossain MB, et al. Polymerase chain reaction-based genotype classification among human Blastocystis hominis populations isolated from different countries. Parasitol Res. 2004; 92(1):22-9. doi:10.1007/s00436-003-0995-2.

10. Noel C, Dufernez F, Gerbod D, Edgcomb VP, Delgado-Viscogliosi P, Ho LC, et al. Molecular phylogenies of Blastocystis isolates from different hosts: implications for genetic diversity, identification of species, and zoonosis. J Clin Microbiol. 2005;43(1):348-55. doi:10.1128/JCM.43.1.348-355.2005.

11. Abe N. Molecular and phylogenetic analysis of Blastocystis isolates from various hosts. Vet Parasitol. 2004:120(3):235-42. doi:10.1016/j.vetpar.2004.01.003.

12. Bohm-Gloning B, Knobloch J, Walderich B. Five subgroups of Blastocystis hominis from symptomatic and asymptomatic patients revealed by restriction site analysis of PCR-amplified 16S-like rDNA. Trop Med Int Health. 1997;2(8):771-8.

13. Yan Y, Su S, Lai R, Liao H, Ye J, Li X, et al. Genetic variability of Blastocystis hominis isolates in China. Parasitol Res. 2006;99(5):597-601. doi:10.1007/ s00436-006-0186-Z.

14. Souppart L, Sanciu G, Cian A, Wawrzyniak I, Delbac F, Capron M, et al. Molecular epidemiology of human Blastocystis isolates in France. Parasitol Res. 2009;105(2):413-21. doi:10.1007/s00436-009-1398-9.

15. Li LH, Zhang XP, Lv S, Zhang L, Yoshikawa H, Wu Z, et al. Cross-sectional surveys and subtype classification of human Blastocystis isolates from four 
epidemiological settings in China. Parasitol Res. 2007;102(1):83-90. doi:10. 1007/s00436-007-0727-0.

16. Stensvold CR, Alfellani MA, Norskov-Lauritsen S, Prip K, Victory EL, Maddox C, et al. Subtype distribution of Blastocystis isolates from synanthropic and zoo animals and identification of a new subtype. Int J Parasitol. 2009;39(4): 473-9. doi:10.1016/j.jijpara.2008.07.006.

17. Parkar U, Traub RJ, Vitali S, Elliot A, Levecke B, Robertson I, et al. Molecular characterization of Blastocystis isolates from zoo animals and their animalkeepers. Vet Parasitol. 2010;169(1-2):8-17. doi:10.1016/j.vetpar.2009.12.032.

18. Souppart L, Moussa H, Cian A, Sanciu G, Poirier P, El Alaoui H, et al. Subtype analysis of Blastocystis isolates from symptomatic patients in Egypt. Parasitol Res. 2010;106(2):505-11. doi:10.1007/s00436-009-1693-5.

19. Dogruman-Al F, Dagci H, Yoshikawa H, Kurt O, Demirel M. A possible link between subtype 2 and asymptomatic infections of Blastocystis hominis. Parasitol Res. 2008;103(3):685-9. doi:10.1007/s00436-008-1031-3.

20. Dominguez-Marquez MV, Guna R, Munoz C, Gomez-Munoz MT, Borras R. High prevalence of subtype 4 among isolates of Blastocystis hominis from symptomatic patients of a health district of Valencia (Spain). Parasitol Res. 2009;105(4):949-55. doi:10.1007/s00436-009-1485-y.

21. Stensvold CR, Christiansen DB, Olsen KE, Nielsen HV. Blastocystis sp. subtype 4 is common in Danish Blastocystis-positive patients presenting with acute diarrhea. Am J Trop Med Hyg. 2011;84(6):883-5. doi:10.4269/ ajtmh.2011.11-0005.

22. Tan TC, Suresh KG, Smith HV. Phenotypic and genotypic characterisation of Blastocystis hominis isolates implicates subtype 3 as a subtype with pathogenic potential. Parasitol Res. 2008;104(1):85-93. doi:10.1007/ s00436-008-1 163-5.

23. Tan TC, Ong SC, Suresh KG. Genetic variability of Blastocystis sp. isolates obtained from cancer and HIV/AIDS patients. Parasitol Res. 2009;105(5): 1283-6. doi:10.1007/s00436-009-1551-5.

24. Wong KH, Ng GC, Lin RT, Yoshikawa H, Taylor MB, Tan KS. Predominance of subtype 3 among Blastocystis isolates from a major hospital in Singapore. Parasitol Res. 2008;102(4):663-70. doi:10.1007/s00436-007-0808-0.

25. Jantermtor S, Pinlaor P, Sawadpanich K, Pinlaor S, Sangka A, Wilailuckana C, et al. Subtype identification of Blastocystis spp. isolated from patients in a major hospital in northeastern Thailand. Parasitol Res. 2013;112(4):1781-6. doi:10.1007/s00436-012-3218-x.

26. Yoshikawa H, Dogruman-Al F, Turk S, Kustimur S, Balaban N, Sultan N. Evaluation of DNA extraction kits for molecular diagnosis of human Blastocystis subtypes from fecal samples. Parasitol Res. 2011;109(4):1045-50. doi:10.1007/s00436-011-2342-3.

27. Parkin DM. The global health burden of infection-associated cancers in the year 2002. Int J Cancer. 2006;118(12):3030-44. doi:10.1002/ijc.21731.

28. Chan KH, Chandramathi S, Suresh K, Chua KH, Kuppusamy UR. Effects of symptomatic and asymptomatic isolates of Blastocystis hominis on colorectal cancer cell line, HCT116. Parasitol Res. 2012;110(6):2475-80. doi:10.1007/s00436-011-2788-3.

29. Chandramathi S, Suresh K, Kuppusamy UR. Solubilized antigen of Blastocystis hominis facilitates the growth of human colorectal cancer cells, HCT116. Parasitol Res. 2010;106(4):941-5. doi:10.1007/s00436-010-1764-7.

30. Qadri SM, Al-Okaili GA, Al-Dayel F. Clinical significance of Blastocystis hominis. J Clin Microbiol. 1989;27(11):2407-9.

31. Abdulsalam AM, Ithoi I, Al-Mekhlafi HM, Ahmed A, Surin J, Mak JW. Drinking water is a significant predictor of Blastocystis infection among rural Malaysian primary schoolchildren. Parasitology. 2012;139(8):1014-20. doi:10.1017/ S0031182012000340

32. Nimri LF. Evidence of an epidemic of Blastocystis hominis infections in preschool children in northern Jordan. J Clin Microbiol. 1993;31(10):2706-8.

33. El Masry NA, Bassily S, Farid Z, Aziz AG. Potential clinical significance of Blastocystis hominis in Egypt. Trans R Soc Trop Med Hyg. 1990;84(5):695.

34. Requena I, Hernandez Y, Ramsay M, Salazar C, Devera R. Prevalence of Blastocystis hominis among food handlers from Caroni municipality, Bolivar State, Venezuela. Cad Saude Publica. 2003;19(6):1721-7.

35. Minvielle MC, Pezzani BC, Cordoba MA, De Luca MM, Apezteguia MC, Basualdo JA. Epidemiological survey of Giardia spp. and Blastocystis hominis in an Argentinian rural community. Korean J Parasitol. 2004;42(3):121-7.

36. Al-Braiken FA. Is intestinal parasitic infection still a public health concern among Saudi children? Saudi Med J. 2008;29(11):1630-5.

37. Hawash YA, Dorgham L, el AM A, Sharaf OF. Prevalence of Intestinal Protozoa among Saudi Patients with Chronic Renal Failure: A Case-Control Study. J Trop Med. 2015;2015:563478. doi:10.1155/2015/563478.
38. Koltas S, Ozcan K, Tannverdi S, Paydas S, Baslamish F. The prevalence of Blastocystis hominis in immunosuppressed patients. Ann Med Sci. 1999;8:117-9.

39. Taşova Y, Sahin B, Koltaş S, Paydaş S. Clinical significance and frequency of Blastocystis hominis in Turkish patients with hematological malignancy. Acta Med Okayama. 2000;54:133-6.

40. Katsarou-Katsari A, Vassalos CM, Tzanetou K, Spanakos G, Papadopoulou C, Vakalis N. Acute urticaria associated with amoeboid forms of Blastocystis sp. subtype 3. Acta Derm Venereol. 2008;88(1):80-1. doi:10.2340/00015555-0338

41. Al-Jasser FS, Kabbash IA, Almazroa MA, Memish ZA. Patterns of diseases and preventive measures among domestic hajjis from Central, Saudi Arabia. Saudi Med J. 2012;33(8):879-86.

42. Shujaa A, Alhamid S. Health response to Hajj mass gathering from emergency perspective, narrative review. Turk J Emerg Med. 2015;15(4):172-6. doi:10.1016/ j.tjem.2015.02.001.

43. Hussein EM, Hussein AM, Eida MM, Atwa MM. Pathophysiological variability of different genotypes of human Blastocystis hominis Egyptian isolates in experimentally infected rats. Parasitol Res. 2008;102(5):853-60. doi:10.1007/ s00436-007-0833-z.

44. Ozyurt M, Kurt O, Mølbak K, Nielsen HV, Haznedaroglu T, Stensvold CR. Molecular epidemiology of Blastocystis infections in Turkey. Parasitol Int. 2008:57:300-6.

45. Jones MS, Whipps CM, Ganac RD, Hudson NR, Boorom K. Association of Blastocystis subtype 3 and 1 with patients from an Oregon community presenting with chronic gastrointestinal illness. Parasitol Res. 2009;104(2): 341-5. doi:10.1007/s00436-008-1198-7.

46. Moosavi A, Haghighi A, Mojarad EN, Zayeri F, Alebouyeh M, Khazan $\mathrm{H}$, et al. Genetic variability of Blastocystis sp. isolated from symptomatic and asymptomatic individuals in Iran. Parasitol Res. 2012;111(6):2311-5. doi:10.1007/s00436-012-3085-5.

47. Leelayoova S, Siripattanapipong S, Thathaisong U, Naaglor T, Taamasri P, Piyaraj P, et al. Drinking water: a possible source of Blastocystis spp. subtype 1 infection in schoolchildren of a rural community in central Thailand. Am J Trop Med Hyg. 2008;79(3):401-6.

48. Noel C, Peyronnet C, Gerbod D, Edgcomb VP, Delgado-Viscogliosi P, Sogin $\mathrm{ML}$, et al. Phylogenetic analysis of Blastocystis isolates from different hosts based on the comparison of small-subunit rRNA gene sequences. Mol Biochem Parasitol. 2003;126(1):119-23.

49. Parkar U, Traub RJ, Kumar S, Mungthin M, Vitali S, Leelayoova S, et al. Direct characterization of Blastocystis from faeces by PCR and evidence of zoonotic potential. Parasitology. 2007;134(Pt 3):359-67. doi:10.1017/ S0031182006001582

50. Yoshikawa H, Abe N, Wu Z. PCR-based identification of zoonotic isolates of Blastocystis from mammals and birds. Microbiol. 2004;150:1147-51.

51. Thathaisong U, Worapong J, Mungthin M, Tan-Ariya P, Viputtigul K, Sudatis A, et al. Blastocystis isolates from a pig and a horse are closely related to Blastocystis hominis. J Clin Microbiol. 2003;41(3):967-75.

52. Rajah Salim H, Suresh Kumar G, Vellayan S, Mak JW, Khairul Anuar A, Init I, et al. Blastocystis in animal handlers. Parasitol Res. 1999;85(12):1032-3.

\section{Submit your next manuscript to BioMed Central and we will help you at every step:}

- We accept pre-submission inquiries

- Our selector tool helps you to find the most relevant journal

- We provide round the clock customer support

- Convenient online submission

- Thorough peer review

- Inclusion in PubMed and all major indexing services

- Maximum visibility for your research

Submit your manuscript at www.biomedcentral.com/submit
( BiolMed Central 